\title{
Suzuki Erken Yaş Keman Eğitiminde Çalışma ve Ders Uygulamalar1
}

\section{Methods of Planning Home Practice and Lessons in Suzuki Early Age Violin Education}

\section{Zehra Sak Brody}

Prof., Yaşar Üniversitesi Sanat ve Tasarım Fakültesi Müzik Bölümü

email: zehra.brody@yasar.edu.tr (DORCID ID: https://orcid.org/0000-0001-7988-1274

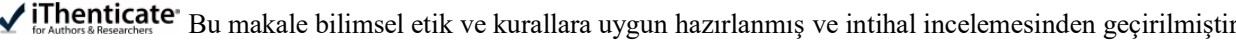

Atıf (APA 6)/To cite this article

Sak Brody, Z. (2020). Suzuki erken yaş keman eğitiminde çalıșma ve ders uygulamaları. Atatürk Üniversitesi Güzel Sanatlar Enstitüsü Dergisi, 26(Müzik Özel Sayıs1), 390-395. doi: https://doi.org/10.35247/ataunigsed.586145

Makale Gönderim Tarihi/Received: 03/07/2019

Makale Kabul Tarihi/Accepted: 17/02/2020

Makale Yayın Tarihi/Published: 25/03/2020

Review Article / Derleme Makalesi

\section{Öz}

Suzuki Erken Yaș Müzik Eğitimi, Japon kemancı ve pedagog Shinichi Suzuki'nin (1898-1998) II. Dünya Savaşı sonrasında geliștirdiği bir müzik öğretim yöntemidir. Keman için geliştirilmiş, daha sonra başka enstrümanlara da adapte edilmiştir. Eğitim, enstrüman öğretmeye odaklı olsa da ana felsefesi küçük çocuklara müziği sevdirebilmektir. Çocuk psikolojisini ön planda olduğu bu sistem ile küçük yaştaki çocuklara ulaşmak ve becerilerini en uygun zamanda ve en doğru şekilde geliştirmek ise metodun ana fikrini oluşturur.

Suzuki eğitimi çocuğu 2 yaşından itibaren derslere başlatır. Enstrüman öğrenmek için en iyi zaman, büyüme çă̆ında kritik dönem dediğimiz 2-7 yaş arasıdır. Suzuki Eğitimi, çocuk ve eğitim psikolojisi barındıran bir felsefeye dayalıdır ve altında çok sistematik bir yöntem vardır. Bu yöntemde hiçbir adımın atlanmadan çalışılması ve eğitimin temel felsefesinin altında yatan tüm prensiplerin uygulamaya adapte edilmesi büyük önem taşır. Ders uygulamalarında bu sistematik örgü çok küçük yaştaki çocuklar için özellikle detaylı bir şekilde çizilmiştir ve doğru şekilde uygulanması şarttır.

Literatür tarama yöntemiyle hazırlanan bu çalışma, Suzuki eğitmeni olmak isteyen ya da metodun uygulanışındaki teknikleri verdikleri eğitimlerde kullanmak isteyen eğitmenlere fayda sağlamak için yol gösterici, pratik bir kılavuz niteliğindedir. Amaç, Türkiye'de henüz çok tanınmayan bu metodun işleyişi hakkındaki bilgiler ışığında yöntemin önemine dikkat çekerek metodun erken yaş müzik eğitimine olan katkısını ortaya koymaktır.

Çalışmada, Suzuki Müzik Eğitimi Metodu kapsamında genel olarak cok küçük yaștaki çocuklara keman öğretme aşamasında izlenilen yollar, uygulama esasları, ev çalışmaları ve derslerin nasıl planlandığı açıklanmış ve paralel olarak metodun ana prensiplerine değinilmiştir.

Anahtar Kelimeler: Suzuki Metodu, Shinichi Suzuki, Erken Yaş Müzik Eğitimi

\begin{abstract}
Suzuki Early Age Music Education was created after the World War II by Japanese violinist and pedagogue Shinichi Suzuki (1898-1998). It was developed for the violin and later adapted to other instruments. "Suzuki Philosophy" covers all instruments and aims to make young children love music. The main idea of this approach, which contains psychological elements, is reaching out to children at an early age and developing their skills at the most appropriate time and in the most accurate way.
\end{abstract}

Suzuki Education starts the child from the age of 2. The best time to learn the instrument is between the ages of 2-7, a period which is referred to as the critical period of growth. Suzuki's education philosophy includes elements of child psychology and educational psychology and is a very systematic method. In this method, it is very important for teachers not to skip any steps and to apply all the principles underlying the basic philosophy of education. These principles must be systematically interwoven in a particularly detailed way for very young children and must be applied correctly.

This article, prepared by reviewing the literature, is intended to serve as a guide for those who wish to become Suzuki teachers, or who wish to incorporate Suzuki techniques into their lessons. The study is also intended to draw attention to the functioning of this method, which is not yet well known in Turkey, and to demonstrate the contribution of the method to early age music education.

In the study, ways to teach violin to very young children, practice principles, home practice, and lesson planning within the Suzuki Music Education Method has been explained, and in parallel, the main principles of the method have been described

Key Words: Suzuki Method, Shinichi Suzuki, Early Age Music Education

\section{Giriş}

Suzuki yaklaşımı, çocuğa müziği doğal bir yolla tanıtmayı amaçlar. Müziğin, çocuğun hayatının doğal bir parçası olmasına, dolayısıyla enstrüman öğrenme aşamasında da severek ilerlemesine yardımcı olur. Çocuk bir şeyi severek ve eğlenerek yaparsa öğrenir. Çocuğa müziği sevdirerek öğretmek ise Suzuki’nin asıl amacıdır.

Suzuki yaklaşımı, sadece enstrüman çalma odaklı değildir. Çocuğu bir bütün olarak geliştirmeyi ve potansiyelini ortaya çıkartmaya yardım etmeyi de amaçlar. Eğitimin amacı sadece büyük sanatçılar yetiştirmek değil, tüm çocuklara müziği sevdirmek ve müzikle gelen mutluluğu bulmaları için yardım etmektir (Garson, 1973, s. 45). 
Suzuki yaklaşımında; çocuk enstrüman öğrenmeye erken yaşta başlar, nota okumak enstrüman çalmayı öğrendikten sonra başlar, ebeveynler derslere katılır ve eğitime dahil edilir, çocuk için rahat ve eğlenceli bir öğrenme ortamı yaratılır, kendi içinde derecelendirilmiş özel literatür kullanılır, motivasyon için grup dersleri sisteme dahil edilmiştir, parça tekrarı/pekiştirme etkin bir şekilde kullanılır, öğrenciler arasında rekabet değil paylaşım yaratılır ve ana hedef olarak kendini geliştirmek ön sıraya çıkar (Kendall, 1986, s. 56-57). Suzuki sisteminin görülen en önemli farklarından biri denetimli öğretmenlik uygulamasıdır. Öğrenciler öğretmenlik becerileriyle ilgili öğrendiklerini bu derslerde uygulama ve geribildirim alma şansını yakalamaktadırlar (Sever, 2018, s. 44).

Suzuki Keman Metodunun birinci kitabı (Keman Okulu I) bu metodun felsefesini ve ana fikrini çok iyi bir şekilde vurgulamaktadır. Özellikle kitabın başlangıcı olan Twinkle (Yaşasın Okulumuz) şarkısı üzerine yazılmış "Beş Ritmik Varyasyon ve Tema”, Suzuki Eğitim Metodunun nasıl işlediğini gösteren mükemmel bir örnektir. Bu varyasyonların öğretilmesindeki teknik neredeyse tüm kitabın öğretim şeması olmuştur. Her ne kadar öğretim felsefesi aynı olsa da varyasyonların öğretim tekniği çocuğun öğrenme hızına, yaşına ve kişiliğine göre ve eğitimciden eğitimciye farklılık gösterebilir. İzlenmesi gereken adımlar ve tüm teknikler ayrıntılı ve kapsamlı bir şekilde öğretilmelidir.

Çalışmada kullanılan, izlenen ve açıklanan bütün adımlar metodun genel çatısı altında uygulanan tekniklerdir ve metodun uygulama aşamasıyla ilgili yoğunlukla pratik bilgilere dayanarak açıklanmıştır. Örneklerle gösterilen çalışma ve ders uygulamaları, Suzuki Eğitmen Eğitimleri ve Seminerleri temel alınarak, Suzuki eğitmenlerinin genel olarak uyguladığı şekilde sunulmuştur. Suzuki eğitmenleri tüm uygulamalara kendi tecrübelerini de katarak metodu takip ederler.

Suzuki Metodu ilk olarak keman için yazılıp sonradan diğer enstrümanlara uygulanmıştır. Bu çalışmada verilen örnekler çerçevesinde diğer enstrümanların da benzer yaklaşımları ve teknikleri kullandığı söylenebilir, yani keman örneği bu noktada temel olarak her enstrüman için düşünülmelidir.

\section{Yöntem}

Araştırma Betimsel Modele dayalı nitel bir araştırmadır. Model dahilinde literatür taraması yapılarak, Dünyaca ünlü keman eğitmeni Shinichi Suzuki’nin erken yaş keman eğitiminde izlediği ve önerdiği yöntemler irdelenmiştir.

\section{Bulgular}

\subsection{Dersin bölümleri}

Dersler ve ev çalışmaları üç bölüme ayrılır. Bu üç bölümün her derste tekrarı önemlidir fakat her ev çalışmasında uygulanması gerekmez. Bölümlerden biri uzun süre çalışılmazsa genel olarak derslerin verimi ve çocuğun ilerleme hizı azalır.

1. Bölüm. Yeni parça üzerinde çalışma: Her çocuğun öğrendiği yeni parçayı çalışması beklenir. Bu çalışma, parçayı CD kayıtlarından dinlemekten, zor pasajların yavaş yavaş çalışılmasına kadar herhangi bir etkinlik olabilir. Önemli olan yeni parçayı her gün duymak, çalmak ve öğrenmeye çalışmaktır.

2. Bölüm. Öğrenilmiş parçaların tekrarlanarak pekiştirilmesi: Tekrar, Suzuki Metodunun ana prensiplerinden biridir. Öğrenilmiş parçanın tekrar tekrar çalınması parçaları hep taze tutar, müzikal ve teknik olarak daha ileri bir seviyeye götürür. Ayrıca, öğrenilmiş parçaların unutulmaması, öğrencinin elinde hazır bir repertuvar olmasını sağlar. Bu da çocuğa çalışma hevesi, güven ve motivasyon sağlar.

3. Bölüm. İleride gelecek teknik pasajların öğrenilmesi: Aileler çocuklarla evde tekrar çalışmasını rahatlıkla yapabilseler de yeni tekniklerin ve teknik problemlerin ne zaman çocuğa gösterileceğini bilemezler. Normal düzeyde ilerleyen bir çocuğa yeni tekniğin eğitmen tarafından parça içinde gelmeden önce tanıtılması ve öğretilmesi gerekir. Çocuk yeni parça içindeki teknik problemi çözmüş olarak parçayı çalmaya başlarsa kendini daha rahat ve güvende hisseder, parçayı korkmadan çalar (Salone Kay, 1985, s. 16-18).

\subsection{Dersin genel prensipleri}

Derslerin uzunluğu çocuğun yaşına, ihtiyacına ve yapabilirliğine göre değişir. Bazen yeni başlayanların dersleri 10 dakika bile sürebilse de çocuk annesi ile birlikte diğer çocukların derslerini de dinleyeceği için öğrenme süreci devam eder. Yetenek Eğitiminde çok küçük çocukların derslerinin büyüklere oranla çok daha kısa olduğu bilinir. Bu yüzden bazı aileler haftada iki, hatta üç ders yapacak şekilde programlarını düzenlerler (Suzuki, 1996).

Kitabın başındaki basit melodiler basit ritimlerden oluşur. Keman kitabının başında çalış pozisyonu daha kolay olan mi ve la tellerinde yazılmış ve sadece üç parmağın kullanıldığı parçalar vardır. Dördüncü parmağın kullanılması ise kitabın ortalarında başlar. İlerleyen parçalarda önce parçanın en zor kısmı çalışılır. Bu kısımlar eğitmenin uygun gördüğü gamlar ve egzersizlerle desteklenir. Zor ve yeni teknik gerektiren kısımlar çözüldükten 
sonra parça cümlelere bölünerek çalışılır. Böylece çocuk küçük adımlarla ve kolay egzersizlerle zorlukları bölerek aşar. Her parça ve her kitabın incelikle planlanmış bir sırası vardır. Her parça bir sonrakini hazırlar.

Suzuki her zaman çocukların birbirlerinin derslerini, özellikle de kendilerinden büyük öğrencilerin dersini izlemeleri gerektiğini savunmuştur. İleri düzey öğrenciler olmadan başlangıç öğrencilerine motivasyon sağlamak zordur. Tipik bir bireysel derste, ders stüdyosunda mutlaka diğer çocukların derslerini izleyen aileler ve öğrenciler olur. Çocuklar çoğu zaman başkaları için keman çalmaktan ve diğer çocukları dinlemekten zevk alırlar. Ayrıca yeni başlayan bir öğrenci diğer çocukların derslerde düzgün ve disiplinli davrandıklarını gözlemlerse aynı şekilde yönlenmiş olur. Aksi davranışların da sadece kendisi değil hiçbir öğrenci için toleransı olmadığını görür. Bu, çevrenin ve bulunduğu ortamın çocuğun eğitiminde ne kadar önemli olduğunu gösteren önemli bir kanıttır. Özellikle bu yeni tecrübeyle ilgili endişe ve korku yaşamaması için çocuğun derslere başlamadan önce anne veya babasıyla ders izlemesi çok önemlidir. Bu, çocuğu rahatlatır ve derslere başladığında kendini bildiği bir ortamda ve güvende hissetmesini sağlar (Starr, 1976, s. 7-8).

Derslerde çocukların ara sıra kendinden daha ileri seviyedeki diğer çocuklarla çalması önemlidir. Eğitmen de sık sık çocukla birlikte çalmalıdır. Öğretmen veya diğer çocuk daha büyük ve güzel bir ton ile daha çabuk bir şekilde parçayı çalıyor olabilir. Çocuk, öğretmeninin veya kendinden büyük öğrencilerin tonuna ve tekniğine kendini uydurmaya çalışacaktır. Suzuki bunun, yarışma ruhu ile yapılmadığı sürece, olumlu bir dış uyarı olacağını savunur.

Her derste öğretmen, çocuğun çalıştığı parçayı kesmeden sonuna kadar bir defa dinler. Çocuk hata yapsa da parçayı sonuna kadar çalabilmeye yönlendirilmelidir. Bu, çocuğu ileride çıkacağı konserlere hazırlayıcı mükemmel bir çalışmadır, ayrıca çocuğu çaldığına odaklanmayı öğrenmesi için eğitir. Bazı eğitmenler performansın devamlılığı için çocuğun çaldığı parçayı içinden notalarıyla söylemesini tavsiye eder.

Suzuki Keman Okulu 10 kitaptan oluşur. Genelde nota okumak öğrenciye 3. kitabın sonuna kadar öğretilmez. Çocuğun yaşına ve öğrenme hızına göre bu, 2. kitap sonunda da başlayabilir. Böylelikle eğitimin en önemli unsuru olan, duruş ve çalış pozisyonlarını doğru kavrama aşamasında çocuğun dikkati ikiye bölünmüş olmaz. Nota okumayı öğrenene kadar, çocuğun hafizası, müzikalitesi ve çalma becerisi de doğru bir şekilde gelişmiş olur. Nota okumayı öğrenmeden önce duruş, el-kol pozisyonları ve yay tutma problemleri çözülmüş olmalıdır ki çocuğun dikkati yeniliklere açık olabilsin.

Çocuk nota okumayı öğrenmiş olduğunda bile derslerde her şeyi ezbere çalması beklenir. Bu uygulama çocuğun hafızasını geliştirecek ve konserlerde ezbere çalma rahatlığı kazandıracaktır. Çocuk eğer nota ile çalışır ve derslerde de nota ile çalarsa kendini korumasız ve güvensiz hissedecek ve konserlerde iyi bir performans gösteremeyecektir (Suzuki, 1969, s. 16).

Öğrenci enstrümanını çalabilmeye başladığı andan itibaren grup çalışmalarına dahil edilir. Oyun odaklı grup dersleri çocuğun motivasyonunda çok büyük bir rol oynar. Grup dersleri ayrıca çocuğun sosyalleşmesi ve paylaşımlarda bulunabilmesi için de mükemmel bir ortam yaratır.

\subsection{Yeni başlayanlar için çalışma planı ve uygulama örnekleri}

Her dersin başlangıcında öğrenci, öğretmenine olan saygısını göstermek için elinde kemanı ile öğretmenine eğilerek selam verir. Öğretmeni de bu saygının karşılığını öğrencisine selam vererek gösterir. Dersin sonunda aynı selam tekrarlanır. Dersin başladığı ve bittiğini belirten bu iki selam arasında çocuk öğretmenine tüm dikkatini vermekle yükümlüdür (Starr, 1976, s. 52).

Yeni başlayan öğrenci, öğreneceği parçayı dersinden çok daha önce evde çok defa dinlemiş olmalıdır. İlk derslerde önce, iki ayak üzerinde rahat ve dengeli bir duruş pozisyonu öğrenilir. Dizler geri atılmamalı, vücut esnekliğini koruyacak şekilde yumuşak ve hareketli olmalıdır. Bir enstrüman çalarken tüm vücudun rahatlığı en önemli noktadır. İleride doğabilecek tüm sorunların temel nedeni yanlış ve doğal olmayan bir duruştur. Çalmaya başlamadan önce tüm vücudu rahatlatıcı küçük egzersizler yapılabilir: "Parmak uçlarında dur ve eller yukarıda havaya doğru uzat". Sonra belden kıvrılarak vücudu aşağı bırak, eller yere doğru sarksın ve sağa sola hafifçe sallansın; boyun ve omuzlar gevşek. Tekrar parmak uçlarına kalk ve elleri geniş bir açıyla aşağı yukarı hareket ettir”. Eğitmen, bunun gibi çocuğun dik durmasına yardımcı olacak, kaslarını rahatlatacak ve sadece fiziksel değil psikolojik olarak da derse hazırlayacak birçok egzersiz yaratabilir (Starr, 1976, s. 61).

Her derste öğretmen öğrenilecek parça veya parçaları öğrenciye çalar. Daha sonra eğer parçanın sözleri varsa şark1 olarak birlikte sözleriyle söylerler. Bu, çocuğun çalacağı parçaya yakınlaşmasını sağlar. Şarkı söylemek, çocuğun kulağının gelişmesi ve doğru entonasyonun kafasında oturmasını sağlamak için devamlı olarak derste yapılan bir aktivitedir. Çocuk bu şekilde her ders entonasyon çalışması yapmış olur. Entonasyon çalışmalarında çocuğa ilk önce Mi ve La telleri ve bu tellerin tınısı öğretilir. Daha sonra öğretmen telleri birer birer çalar ve çocuktan bunun hangi tel olduğunu tahmin etmesini ister. Daha sonra öğrenci gözlerini kapatarak tınıyı dinler ve tahminlerde bulunur. Bir sonraki aşamada öğretmen bu tellerden birinde kısa bir melodi çalar ve çocuğun bu melodinin hangi tel üzerinde çalındığını tahmin etmesini ister. 
Öğrenilecek ilk ritimler önce el çırparak çalışılır. Bu noktada, ritimleri daha rahatlıkla öğrenebilmek için ritimlere isim verip hecelere ayırarak şarkı gibi söylemek de bir yöntemdir. Ritimler ayrıca kafaya, omuzlara, bacaklara elle vurarak ya da bir kalemle duvara, yere vurarak, ayaklarla yere vurarak farklı şekillerde de eğlenceli olacak bir şekilde tekrarlanabilir. Keman eğitiminde yeni parça öğrenilirken çoğu zaman parçanın en başından başlanmaz. Önce parçanın ritmi, mutlaka elle çırpılarak ve şarkı olarak söyleyerek öğrenilir. Yeni ritmi öğrenirken dans veya vücut hareketleriyle akılda kalıcılığını desteklemek dersi de renklendirir. Çocuğun yeni bir parçayı öğrenirken, ritmi ve sağ kolun hareketini kemandan bağımsız bir şekilde öğrenmesi çocuğa kolaylık sağlar. Daha sonra ritim, yayı dikey bir şekilde tutup havada hareket tekrarlanır. Sonraki etapta ise nota uzunluklarına göre yayı bölerek ritmin yayın hangi kısmında çalınacağını öğrenilir. Öğrenci zaten parçayı kulaktan çok iyi bildiği için ritmi kavramakta zorluk çekmez.

Ritim öğrenilirken, eğitmen çocuğun sol el parmaklarını, parmak numaralarına dikkat çekerek tele yerleştirir. Bunu yaparken, sağ el işaret parmağı (pizzicato) ile telleri çekerek çocuğun sesleri duymasını sağlar (Starr, 1983). Çoğu zaman kemanın siyah tuşunun üzerine parmakların konulacağı noktaları belirten renkli bantlar konur. Bu bantlar eğitim süresince çocuğun ilerleme hızına göre teker teker çıkartılır. Bu bantlar sayesinde öğrenci parmakları tellere kendi yerleştirebilecek hale gelecektir.

Duruş ve ritimler öğrenilirken, parmakların numaraları ve yay tutma çalışmaları başlar. İlk etapta yay çok ağır geleceği için yay yerine kalem ya da benzeri daha hafif plastikten ya da tahtadan aparatlar kullanılabilir. Çocuk kalemi doğru şekilde tutabildikten sonra, daha önceden elle çırpılarak öğrenilen ritimler, kalem havada dikey bir şekilde tutularak aşağı yukarı çekme-itme hareketiyle tekrarlanır. Daha sonra bu hareket gerçek yay ile tekrarlanır. Öğretmen çocuğun sağ el parmaklarının içini (yayın parmaklarla temas edeceği noktaları) boyalı kalemle işaretler. Çocuk parmaklarını bu işaretli kısımları üzerine gelecek şekilde yerleştirerek yayı tutmalıdır. Yay ilk etapta çocuğa ağır gelirse yay sol omuza konularak, vücut keman çalma pozisyonundayken de çalışılabilir.

Yay tutma, duruş ve ritim çalışmaları devam ederken keman omuza yerleştirilir. Temel duruş pozisyonunda keman çocuğun çenesinin altına yerleştikten sonra eğitmen parmağıyla çocuğun kafasından başlayıp burnunun üzerinden kemanın tellerine parmağıyla düz bir çizgi çizmeye çalıșır. Doğru pozisyonda, çocuğun burnu kemanın salyangozuna bakıyor ve keman sol ayağının üzerinde duruyor olmalıdır. Bu pozisyonda gözler de tellere çevrilmiș olmalıdır. Omuz ve boyunu kasmadan rahat bir tutuş pozisyonu bulabilmek için kemanın altına yastık veya sünger konularak destek yapılır. Çocuk kemanı sol el ile tutmadan sadece çene ve omuz ile rahat bir şekilde tutabilmelidir. $\mathrm{Bu}$ aşamada, o ana kadar çalışılan ritimler Mi ve La tellerinde çalınmaya başlanır.

Çocuk parmaklarını hangi tellere, nasıl yerleştirmesi gerektiğini öğrenir. İlk olarak La teline ilk üç parmak yerleştirilir daha sonra Mi telinde aynı şey uygulanır. La ve Mi telleri üzerinde küçük gamlar çalışılır. 4. parmağın yerleştirilmesi daha zor olduğundan sonraya bırakılır. Pizzicato çalışmaları, büyük oranda ince kas koordinasyonu gerektirir. Öğrenci yeni parçayı önce yaysız bir şekilde teli sağ-el işaret parmağıyla çekerek (pizzicato) çalabilir. Öğretmen ilk parçayı parmak numaralarının isimleriyle söyler ve çocuk her ölçüyü öğrenene ve öğretmenden yardım almadan söyleyene kadar tekrar eder. Yani parçanın sözleri yerine parmak numaralarının isimleriyle şarkı söylenir. Çocuk bunu yaparken sol el parmak hareketlerini de öğrenebilmek için sol el 1, 2 ve 3. parmaklarını parçanın ritmi içinde sol el başparmağına dokundurarak hareket ettirir. Ev çalıșmalarından sonra çocuk parçanın parmak hareketlerini kemanın üzerinde göstermeye hazırdır. Parçanın yay hareketleri zor ise parçayı nota isimleriyle söylerken sağ eliyle havada (yayı tutmadan) yay hareketlerini öğretmenle birlikte taklit eder. Daha sonra yayı tutarak havada veya yayı sol omuzuna koyarak hareketleri tekrarlar.

Yay ile sol el parmakların koordinasyonu çocuk parmaklarını doğru şekilde basıp parçanın ritmini tamamıyla öğrendiğinde başlar. Çocuk parçayı kayıtlardan dinlemeye devam etmektedir ve yavaş yavaş sol el parmak hareketleri ve sağ el yay hareketlerini birleştirerek parçayı keman üzerinde çalmayı öğrenir. Parçayı önce ölçü ölçü, daha sonra cümlelere ayırarak çalar. Öğrenci öğretmenin direktifleri ile yayı nasıl çekip parmakları nasıl hazırlayacağını öğrenerek melodiyi çıkarmaya çalışır. Başlangıçta notaların ismi değil parmakların numaraları ve parmakları nasıl yerleştirecekleri öğretilir. Çocuk melodiyi kulaktan çok iyi bildiğinden yanlış parmak koyduğunda yanlışını duyar. Yayın hangi uzunlukta çekilip itileceği, notanın uzunluğuna göre yayın uzunluğunun ne olması gerektiği gösterilir ve bu hareketler çoğu zaman yayın üzerine konular renkli bantlarla çocuğun görüp uygulayabileceği bir şekle getirilir.

Çocuk parçanın parmak numaralarını öğrendikten ve sağ el yay hareketleriyle birleştirdikten sonra teknik, müzikalite ve entonasyon çalışması yapmak için hazırdır. Yeni parça öğrenilmeye başlandığında ise eski parçalar, çocuğun her an çalabileceği hazır materyaller olarak kalabilmesi için sürekli tekrarlanır. Yeni parçanın notaları/parmak numaraları eski parçalar tekrar edilirken öğrenilir.

\subsection{Motivasyon ve tekrar oyunları}

Çocuğun doğru hazırlanmış bir ortamda büyümesi, çevresi ile etkileşimi, anne ve babadan gördüğü davranışlar ve eğitmeniyle olan ilişkisi motivasyonu etkiler. Bunun yanı sıra, çok küçük yaştaki çocukların enstrüman çalmaya 
yönlendirilmesinde izlenecek yolların hepsinde, doğru motivasyon ile yapılan eğlenceli, oyun oynamaya dayalı dersler ve ev çalışmaları büyük bir önem taşır.

Dersler ne kadar oyun odaklı olsa da, çaldığı parçayı sürekli tekrar ederek pekiştirme çalışmaları öğrenci için bazen sıkıcı olabilir. Özellikle küçük yaştaki öğrencilere tekrar yaptırmak çok zordur. Suzuki, metodun felsefesi olan çocuğa kemanı sevdirme amacı ile bu probleme de çözüm getirmiş ve eğitmenlere kendi yöntemlerini bulmaları için yol göstermiştir. Suzuki eğitimlerinde ayrıntılı olarak işlenen ders uygulamalarında tüm eğitmenlerin tecrübeleriyle keşfettiği oyunları birbiriyle paylaşarak gelişen bu teknik, sadece eğitmenlere değil ev çalışmalarını teşvik etmek için ailelere de büyük kolaylık sağlamaktadır.

Oyun diye adlandırdığımız her şey teknik çalışma olduğundan mutlaka doğru şekilde uygulanması gerekir. Tekrar oyunlarında, öğrenciye her oyundan önce dikkat etmesi ya da düzeltmesi gereken noktayı hatırlatarak başlatmak tekrar oyunlarının amaca ulaşmasını sağlayacaktır. Öğrenci her tekrarda neye dikkat etmesi gerektiğini bilmelidir. En önemlisi, çocuğun her çalışı doğru duruş ve çalış pozisyonunda olmalı, her tekrar güzel bir ton ile çalınmalıdır (Grilli, 1987, s. 54).

Derslerde kullanılan tekrar oyunları her zaman ilgi görür ve çoğunlukla başarılı sonuçlar verir. Önemli olan, öncelikle tekrarı ne amaçla yaptığınıza karar vermek ve bunu çocuğun anlamasını sağlamaktır. Çocuklar bazı oyunları beceremeyecektir. Bu durumda çok üstelemeden başka bir oyuna geçmekte yarar vardır. Dersi çocuğu hayal kırıklığına uğratmadan, başarısız olma hissi yaratmadan, daha sonra "eğlenceliydi” diyebileceği bir şekilde planlamak en önemli amaçtır. Tekrar Oyunlarında önce problemli kısmı öğrenciye çaldırmalı, sonra doğrusunu gösterip tekrar çaldırmalıdır. Çocuk ne yapması gerektiğini anladıktan sonra eğitmenin vereceği direktiflerle ders renklendirilir.

Birkaç oyun örneği: "Şimdi bakışlar sadece sol elde olsun ve çal". "Bakışlar sadece sağ elde olsun ve çal”. “Gözlerini kapat ve çal”. "Her doğru çalışın için kumbaraya para atalım”. "Sen parmakları koy, ben yayı çekeyim”. "Ben parmakları koyayım, sen yayı çek". "Kafanın üzerine kitap koyalım, kitabı düşürmeden çal". "Sen öğretmen ol, ben öğrenci. Ben çalayım, sen benim yanlışlarımı düzelt". "Parçayı başka telden başlayarak, farklı tonda çalalım!". "Zar atalım, kaç gelirse o sayıda üst üste çal”. "Her doğru çalış için bir çıkartma kazanacaksın!” (Grilli, 1987, s. 171-186).

Suzuki metodunda, küçük yaştaki öğrencilerle derslerin daha eğlenceli geçmesi için tüm eğitmenleri kendi oyunlarını üretmesi gerektiğini tavsiye edilir. Ne kadar ismi oyun olsa da, bu yöntem aslında öğretme biçimini geliştirici ögelerden oluşur. Kurallı ve planlı olması gerekmediği gibi eğitmenin yaratıcılığına ve çocuğun o anki ihtiyacına göre oluşturulabilir. Ayrıca ev çalışmalarında da ailelere yardımcı mükemmel bir tekniktir. Bu oyunlar sadece tekrar için değil, Duruş /Denge, Ton, Entonasyon, Dinleme/ Gözlem, İnce ve Kalın Kas Koordinasyonu, Ritim ve Hızlı Tepki geliştirmek için de oluşturulabilir ve çocuğun motivasyonuna büyük oranda olumlu etkisi vardır. Müzik eğitiminin sürekliliği, eğitmenin ve öğrencinin hayal gücünün derslerde kullanılması ile mümkündür.

\section{Sonuç}

En kritik dönem olan 2-7 yaş arasında verilen müzik eğitimi en önemli ve değerli eğitimdir. Kritik dönemde yanlış ve kötü uygulamalar yüzünden çocukların müzik becerilerinin yanlış bir şekilde şekillendiği çok sık rastlanılan bir durumdur. Suzuki Metodunu anlamak ve uygulayabilmek için öncelikle eğitmen eğitimi sertifikası almış olmanın yanında; Suzuki Yöntemini oluşturan elementler ve yöntemin amacı, yeni öğretim sitillerine bakış, Suzuki eğitiminin tarihçesi ve gelişimi, eğitimde ailenin önemi ve Suzuki pedagojik eğitimi bilinmesi gereken konulardır (European Suzuki Association, 2018).

Suzuki Metodunda ebeveynin, çocuğun ilk ve en önemli öğretmeni olduğu inancı tüm faaliyetlerde merkezi bir rol oynar. Bebek ve okul öncesi sınıflara ebeveyn katılımı yoluyla, ebeveynler, çocuklarının büyümesi için zenginleştirilmiş doğal bir ortam sağlamakta ortak olmalıdırlar. Çocuğun öğrenme konusundaki doğal zevkini geliştirmek amaç olmalı ve Dr. Suzuki'nin “yaşam boyu öğrenme” felsefesi unutulmamalıdır. Amaç, çocuğa baskıdan arınmış, beceri kazanabileceği bir ortam yaratarak duygusu, disiplin anlayışı ve güzelliği takdir edebilme hissi ve yetisi verebilmektir ("Suzuki Müzik Eğitim Derneği”, t.y.).

Türkiye'de 2000'li yıllardan itibaren müzik eğitimi alanında geliştirilmiş Orff, Suzuki, Kodaly ve Gordon gibi yaklaşımlara ilginin artması ile birlikte adı geçen yaklaşımların eğitim öğretim faaliyetlerini düzenlemek için çeşitli merkezler kurulmaya başlanmıştır. Bu bağlamda Suzuki Müzik Eğitimi Derneği (SMED), çalgı eğitimi üzerine odaklanmış çalışmalar yapmak üzere Avrupa Suzuki Birliği’ne (ESA) bağlı olarak 2008 y1lında kurulmuştur (Sever, 2018, s. 39).

Türkiye'de Avrupa'ya bağlı bir dernek olmasına rağmen Suzuki Metodunun ülkemizde henüz tam anlamıyla anlaşılmamış olması ve dolayısıyla yanlış kullanımı ve metot hakkındaki bilinen bazı yanlış bilgiler belki de konuyla ilgili yeterli Türkçe kaynak olmamasından kaynaklanmaktadır. Suzuki Metodunun Türkiye'de tanınması, 
daha birçok okul öncesi çocuğun müzikle tanışmasına ve müziği sevmesine yardımcı olacaktır. Bu noktada müzik eğitmenlerinin hedefi, Suzuki Metodunu ve erken yaş eğitiminde uygulanan diğer pedagojik yaklaşımları olabildiğince tanımak, Türkiye'de bilinen ve edinilen bilgileri öncelikle orijinal kaynaklarla destekleyerek doğruluğunu saptamak olmalıdır.

\section{Kaynakça}

European Suzuki Association (2018). Teacher training and examinations manual \& teacher training syllabus. Erişim adresi: http://www.digital-e-brochures.com/EuropeanSuzuki/TTraining2018/

Garson, A. (1973). Suzuki and physical movement. USA: Music Educators J.

Grilli, S. (1987). Preschool in the Suzuki spirit. USA: Suzuki Method International.

Kendall, J. (1986). Suzuki's mother tongue method. USA: MEJ: Music Educators Journal. Erişim adresi: https://journals.sagepub.com/doi/abs/10.2307/3401277

Salone Kay, C. (1985). They're rarely too young and never too old to twinkle!. USA: Shar Publications

Sever, G. (2018). Suzuki Öğretmen Yetiştirme Sisteminin İncelenmesi. Kastamonu Eğitim Dergisi. 27(1), 37-46. doi: https://doi.org/10.24106/kefdergi.2247

Starr, W. (1976). The Suzuki violinist. USA: Alfred Music.

Starr, W., \& Starr, C. (1983). To learn with love. USA: Summy-Birchhard INC

Suzuki Müzik Eğitim Derneği. (t.y.). Erişim adresi: http://suzukimuzik.com/

Suzuki, S. (1969). Ability development from age zero. USA: Suzuki Method International.

Suzuki, S. (1996) Sevgiyle ĕgitmek. (J. Yalçın Dittgen ,Çev.). Türkiye: Porte Müzik Eğitim Yayınları. 